\title{
Acute intermittent porphyria: novel missense mutations in the human hydroxymethylbilane synthase gene
}

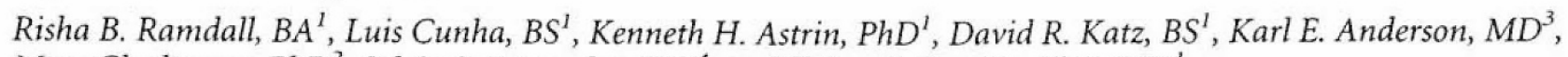
Marc Glucksman, PhD', Sylvia S. Bottomley, $M D^{4}$, and Robert J. Desnick, PhD, MD ${ }^{1}$

\begin{abstract}
Purpose: To identify mutations in families with acute intermittent porphyria, an autosomal dominant inborn error of metabolism that results from the half-normal activity of the third enzyme in the heme biosynthetic pathway, hydroxymethylbilane synthase. Methods: Mutations were identified by direct solid phase sequencing. Results: Two novel missense mutations E80G and T78P and three previously reported mutations, R173W, G111R, and the splice site lesion, IVS1 ${ }^{+1}$, were detected, each in an unrelated proband. The causality of the novel missense mutations was demonstrated by expression studies. Conclusion: These findings provide for the precise diagnosis of carriers in these families and further expand the molecular heterogeneity of AIP. Genetics in Medicine, 2000:
\end{abstract} 2(5):290-295.

Key Words: acute intermittent porphyria, hydroxymethylbilane synthase, HMB synthase, porphobilinogen deaminase, molecular diagnosis

Acute intermittent porphyria (AIP), an inborn error of heme biosynthesis, is one of the few enzymopathies inherited as an autosomal dominant trait. The disease results from the half-normal activity of hydroxymethylbilane synthase, the third enzyme in the heme biosynthetic pathway (EC 4.3.1.8; HMB-synthase; formerly known as porphobilinogen deaminase or uroporphyrinogen I synthase). Clinical onset of AIP typically occurs during or after puberty and is characterized by acute attacks of neurologic dysfunction. These attacks include abdominal pain, hypertension, tachycardia, and various peripheral and central nervous system manifestations. The attacks are precipitated by environmental (e.g., certain drugs, dieting, or starvation), metabolic (e.g., alcohol), and hormonal (e.g., certain steroids) factors that induce hepatic $\delta$-aminolevulinic acid synthase activity, the first and rate-limiting enzyme of heme biosynthesis. ${ }^{1-3}$ With increased activity of this enzyme, levels of the porphyrin precursors, 5-aminolevulinic acid (ALA) and porphobilinogen (PBG) increase, and the halfnormal level of hepatic HMB-synthase activity in AIP patients

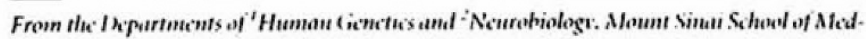

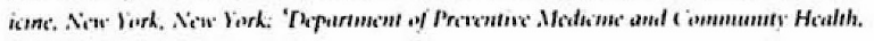

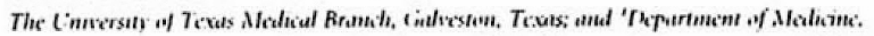

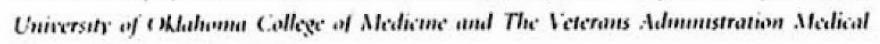
Cinter, ()klahoma (it): Oklahoma.

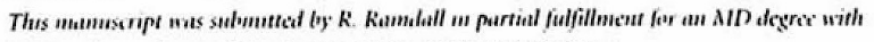

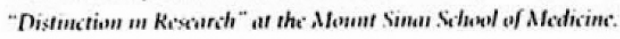

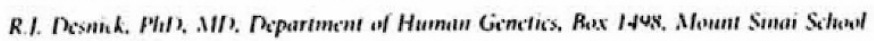

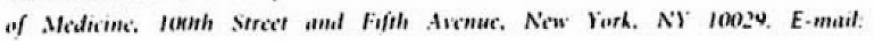
RIDesnichein'mstux.mssm.citu.

Recived: April 3), 3omon.

diciepted: May) 25. 2(kK). is insufficient to prevent pathologic accumulation of these compounds, and acute, life-threatening neurologic symptoms.

Presymptomatic identification of heterozygotes in affected AIP families, and counseling regarding the avoidance of the precipitating factors is crucial in the management of this disease. Symptomatic heterozygotes, who excrete increased urinary levels of ALA and PBG, are easily identified, provided that the diagnosis is considered. In contrast, the diagnosis of asymptomatic heterozygotes ( $~ 80 \%$ of heterozygous individuals), who usually have normal levels of urinary ALA and PBG, has been problematic primarily due to the significant overlap between high heterozygote and low normal values of HMBsynthase activity in erythrocytes. ${ }^{4-9}$ Therefore, efforts have been directed to identify the specific HMB-synthase mutations in each family, particularly because most mutations have been "private," i.e., limited to a single or few families.

HMB-synthase is a monomeric enzyme that catalyzes the head to tail condensation of four molecules of PBG to form the linear tetrapyrrole hydroxymethylbilane. ${ }^{1.2}$ HMB-synthase is encoded by a single $11-\mathrm{kb}$ gene that contains 15 exons and 2 distinct promoters that generate housekeeping and erythroidspecific transcripts by alternative splicing. ${ }^{10-13}$ The housekeeping promoter is in the $5^{\prime}$ flanking region and its transcript contains exons 1 and 3-15, whereas the erythroid-specific promoter is in intron 1 and its transcript is encoded by exons 2-15. The housekeeping and erythroid-specific transcripts encode isozymes of 42 and $40 \mathrm{kDa}$, respectively. "In classic AIP ( $\sim 95 \%$ of the AIP families), both the housekeeping and erythroid-specific isozymes have half-normal activities, whereas in variant AIP (representing $\sim 5 \%$ of AIP families), the house- 
keeping enzyme has half-normal activity, while the erythroidspecific enzyme is expressed at normal levels. ${ }^{14}$

The availability of the full-length cDNA and complete genomic sequences encoding human HMB-synthase permits the identification of the specific lesions in the gene that cause AIP. ${ }^{10-13}$ To date, over 160 mutations causing AIP have been identified; ${ }^{15-17}$ approximately $50 \%$ are point mutations and the rest, splice site mutations, insertions, and deletions. The absence of "common" AIP mutations necessitates identification of the disease causing lesions in each AIP family for accurate presymptomatic diagnosis. In this communication, five HMB-synthase mutations are described, two newly discovered missense mutations in exon 6 (T78P and E80G), and three previously reported mutations, IVS1 ${ }^{+1}, \mathrm{G} 111 \mathrm{R}$ and R173W. Of note, identification of the E80G mutation in members of a previously reported family diagnosed by enzyme assay clarified the genotypic status of at-risk members. ${ }^{4}$

\section{METHODS}

\section{Patient specimens}

Peripheral blood samples were collected from members of five unrelated AIP families of Northern European ancestry with informed consent. Proband 1 and his family were previously described by Bottomley et al. ${ }^{4}$ Genomic DNA was extracted from peripheral blood using the Puregene DNA isolation kit [Gentra Systems, Inc. Minneapolis, MN].

\section{Long-range PCR}

Long-range PCR was performed using two primer sets to amplify the entire HMB-synthase gene $(11 \mathrm{~kb})$ in two fragments, a 4.5 -kb product which included the promoter region through intron 3 and a $5.5 \mathrm{~kb}$ product which contained exon 2 through exon $15 .{ }^{18}$ Using the GeneAmp XL PCR Kit (Perkin Elmer, Foster City, CA) and a PCR Minicycler (M.J. Research, Watertown, MA), an initial incubation was performed at $94^{\circ} \mathrm{C}$ for 1 minute, and then fragments 1 and/or 2 were amplified from genomic DNA in a single or separate reaction(s). The first 16 cycles were performed with denaturation at $94^{\circ} \mathrm{C}$ for 30 seconds and annealing and extension at $65^{\circ} \mathrm{C}$ for 6 minutes. The second 12 cycles were carried out with denaturation at $94^{\circ} \mathrm{C}$ for 30 seconds, and annealing and extension at $65^{\circ} \mathrm{C}$ for 375 seconds, with 15 seconds increments each additional cycle. The final extension step was performed at $72^{\circ} \mathrm{C}$ for 10 minutes. A portion of each PCR product was analyzed by agarose gel electrophoresis to confirm that the long-range reactions were successful, and to identify any gross gene rearrangements. Each PCR product was purified with the High Pure PCR Product Purification Kit (Boehringer Mannheim Corp., Indianapolis, IN).

\section{Sequencing reactions}

Each exon and flanking intronic regions was sequenced using the Amplicycle Sequencing Kit (Perkin-Elmer), according to the manufacturer's instructions with the following modifications. The sense and antisense primers used for sequencing each exon are listed in De Siervi et al. ${ }^{18}$ To a set of four tubes, each containing $2 \mu \mathrm{L}$ of one of the dNTPs, $6 \mu \mathrm{L}$ of the following mixture was added: $4 \mu \mathrm{L}$ of cycling mix (1.25 U of Amplitaq DNA polymerase in $500 \mathrm{mM}$ Tris- $\mathrm{HCl}, \mathrm{pH} 8.9 ; 100 \mathrm{mM}$ $\mathrm{KCl} ; 25 \mathrm{nM} \mathrm{MgCl} ; 0.25 \%$ Tween 20$), 1 \mu \mathrm{L}$ of primer $(20 \mu \mathrm{M})$; $1 \mu \mathrm{L}$ of DNA ( $100 \mathrm{ng}) ; 23 \mu \mathrm{L}$ of $\mathrm{H}_{2} 0$ and $1 \mu \mathrm{L}$ of $\left[\alpha^{-}{ }^{33} \mathrm{P}\right] \mathrm{dATP}$ ( $1 \mu \mathrm{Ci}$, Dupont). After adding one drop of mineral oil, the tubes were placed in the PCR machine (M.J. Research, Watertown, MA) and preheated at $95^{\circ} \mathrm{C}$ for 3 minutes. The cycle sequencing reaction was performed ( 30 cycles) with a denaturation step at $95^{\circ} \mathrm{C}$ for 30 seconds, annealing at $60^{\circ} \mathrm{C}$ for 30 seconds, and extenuation at $72^{\circ} \mathrm{C}$ for 60 seconds. The reaction was stopped by adding $4.5 \mu \mathrm{L}$ of stop solution (95\% formamide; $20 \mathrm{mM}$ EDTA; $0.05 \%$ bromophenol blue and $0.02 \%$ xylene cyanol). After a denaturation step of 3 minutes at $94^{\circ} \mathrm{C}$, the samples were loaded in a $4 \%$ acrylamide solution (19:1) containing $7 \mathrm{M}$ urea gel, preheated at about $50^{\circ} \mathrm{C}$, and electrophoresed at $90 \mathrm{~W}$ for different times, depending on both the region being sequenced and the primer used. When the run was completed, the gel was transferred to a filter paper (Whatman No. 3) with a plastic film, dried for 2 hours at $80-90^{\circ} \mathrm{C}$, and exposed to autoradiographic film (Kodak X-OMAT) for 48 hours.

\section{Dot blot hybridization}

Amplified DNAs from exon 6 of the proband and members of Family 3 were slot-blotted on Hybond $\mathrm{N}^{+}$nylon membrane and then hybridized to allele-specific oligonucleotides (normal allele: $5^{\prime}$-AGACCTAGCA-TACTAGGG-3'; mutant allele: $5^{\prime}$ GCCTCTGTCCCCATCATGAA- $3^{\prime}$ ) using the following conditions: 3-5 mL of Amersham Rapid Hybridization solution was added to a sealable bag, and the pouch was prehybridized for 30 minutes at $42^{\circ} \mathrm{C}$ in a shaking water bath. The $\left[\alpha-\mathrm{P}^{32}\right]$ dATP labeled probe was added to the pouch at a concentration of $1-2 \times 10^{6} \mathrm{cpm}$ per $\mathrm{mL}$ of hybridization solution and replaced in the shaking water bath for 60 minutes at $42^{\circ} \mathrm{C}$. The membrane was removed from the bag and washed at room temperature for 10 minutes in $6 \times \mathrm{SSC}$ and a second time for 10 minutes at $42^{\circ} \mathrm{C}$. The membrane was washed for a third time in $0.5 \times \mathrm{SSC} / 0.1 \% \mathrm{SDS}$ for 10 minutes at $42^{\circ} \mathrm{C}$. The membrane was covered with polyvinylchloride wrap and exposed to $\mathrm{x}$-ray film for 3 hours.

\section{Prokaryotic expression of the missense mutations}

The normal, T78P and E80G HMB-synthase alleles were individually expressed in $E$. coli using the pKK233-2 vector (Pharmacia Biotech., Inc., Piscataway, NJ) as previously described. ${ }^{18.19}$ To introduce the mutations into the normal pKK-HMB-synthase (pKK-HMBS) expression construct, the QuikChange Site-Directed Mutagenesis Kit (Stratagene, La Jolla, CA) was used according to manufacturer's directions. For the T78P and E80G mutations, sense and antisense primers, 5' -GGAGAGAAAAGCCTGTTTCCCAAGGAGCTTGAACATGC- $3^{\prime}$ and $5^{\prime}$-GCATGTTCAAG-CTCCTTGGGAAACAGGCTTTTCTCTCC- $3^{\prime}$ and sense and antisense primers, 5'-GGAGAGAAAAGCCTGTT-

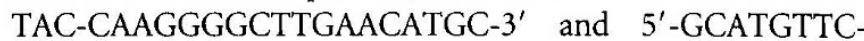


AAGCCCCTTGGTAAACAGGCTTTTCTCTCC-3' were used, respectively. The mutant $\mathrm{pKK} 233-2$ vectors were sequenced before the expression studies to ensure that each contained the indicated mutation. After transfection, bacterial growth, and isopropylthiogalactoside (IPTG) induction, the expressed HMBsynthase activity was assayed as previously described. ${ }^{13,19}$

\section{RESULTS}

Direct solid-phase sequencing of the HMB-synthase gene from five unrelated AIP probands previously diagnosed biochemically (Table 1) identified two new missense mutations and three previously reported lesions (Table 2). All five mutations were initially identified by sequencing the entire exonic region and adjacent intronic and flanking sequences; no other alterations were identified. Each mutation was detected in other, at risk family members, consistent with the expression and/or inheritance of this autosomal dominant acute porphyria. The mutations were confirmed by repeat direct sequencing of genomic DNAs from the proband and/or symptomatic and asymptomatic family members. The two novel mutations are only the second and third mutations identified in exon 6: an adenine to cytosine transversion at cDNA nucleotide (nt) 232 , which predicted the replacement of an uncharged polar threonine by a hydrophobic nonpolar proline, T78P (Fig. la), and an adenine to guanine transition at cDNA nt 239 , which predicted the substitution of a hydrophilic polar glutamic acid by an uncharged polar glycine, E80G (Fig. 1b). To further characterize these base substitutions, pKK-HMB-synthase expression vectors containing either the T78P or the $\mathrm{E} 80 \mathrm{G}$ mutations were constructed, expressed in E. coli, and the enzymatic activity of the mutant proteins was determined. As shown in Table 3 , the residual enzymatic activity of the mutant $\mathrm{T} 78 \mathrm{P}$ protein was $2.5 \%$ of the mean enzymatic activity expressed by the normal allele, whereas the mutant E $80 \mathrm{G}$ protein was $2.4 \%$. That both mutations had markedly decreased HMB-synthase activity confirmed that they were pathogenic lesions.

The three previously reported mutations included an adenine to cytosine transversion at cDNA nt 100 in exon 4, which predicted the replacement of a glutamine by a hydrophilic po-

Table 1

Biochemical diagnostic studies of the AIP probands

\begin{tabular}{|c|c|c|c|}
\hline \multirow[b]{2}{*}{ Proband } & \multicolumn{2}{|c|}{ Urine $(\mathrm{mg} / 24 \mathrm{hr})$} & \multirow{2}{*}{$\frac{\text { Erythrocyte }(\mathrm{nmol} / \mathrm{ml} / \mathrm{hr})}{\text { HMB-synthase }}$} \\
\hline & ALA & PBG & \\
\hline 1 & 24.7 & 60.0 & 11 \\
\hline 2 & 3.0 & 1.6 & 17.0 \\
\hline 3 & - & - & 13 \\
\hline 4 & 3.0 & 8.9 & 15.0 \\
\hline 5 & 20.5 & 33.2 & 40.4 \\
\hline Normal range & $0-7$ & $0-4$ & $20-50$ \\
\hline
\end{tabular}

lar arginine, G111 $\mathrm{R}^{9,18,20}$; a cytosine to thymidine transition of a CpG dinucleotide at cDNA nt 517 in exon 10, which predicted the substitution of a hydrophilic polar arginine by a hydrophobic nonpolar tryptophan, R173 $\mathrm{W}^{21}$; and an $\mathrm{IVS}^{+1}$; a guanine to adenine transition, which altered the invariant $5^{\prime}$ donor splice site of intron 1 from gt to at..$^{22}$ The IVS ${ }^{+1}$ mutation was detected in proband 5 who had normal erythrocyte HMB-synthase activity, but was diagnosed as having AIP on the basis of her symptoms and increased urinary porphobilinogen. The detection of the IVS1 ${ }^{+1}$ mutation identified the proband as having variant AIP. Molecular diagnostic studies of the proband's two offspring indicated that neither daughter had inherited the IVS1 ${ }^{+1}$ mutation (Fig. 2). The G111R lesion was detected only in the proband of Family 3 . The R173W mutation in Family 4 was also identified in the proband's daughter.

The E80G mutation was identified in a large kindred in which Proband 2, his five siblings, and some of their children were previously evaluated for AIP by their erythrocyte HMBsynthase enzymatic activities or increased urinary PBG excretion. ${ }^{4}$ As shown in Figure 3, available family members were tested for the E80G mutation by dot-blot hybridization with allele specific oligonucleotides. DNA testing confirmed the enzyme-based diagnosis of those who previously had normal or low erythrocyte HMB-synthase. In addition, the two family members who were inconclusive by enzyme assay did not have the mutation.

\section{DISCUSSION}

For many genetic disorders, the presymptomatic diagnosis of affected individuals as well as the identification of carriers of recessive genes has been remarkably improved by DNA analyses. Such is the case for AIP, where the biochemical demonstration of the enzymatic deficiency has proven problematic. ${ }^{4-9}$ In asymptomatic heterozygotes with classic AIP who have half normal levels of erythrocyte HMB-synthase activity, the enzymatic diagnosis has been difficult due to significant overlap between low normal and high heterozygote values. In asymptomatic patients with variant AIP, the enzymatic diagnosis is not possible because they have normal erythrocyte HMB-synthase activity, although the levels in liver and other tissues are half-normal. ${ }^{1+}$ Therefore, the identification of mutations causing the classic form, and especially the variant form of AIP, is critical for precise diagnosis and appropriate counseling of affected individuals.

Because sequencing of the HMB-synthase gene in each AIP family is labor-intensive and expensive, initial efforts focused on the identification of informative intragenic polymorphisms, which could identify heterozygotes by pedigree analysis. ${ }^{13}$ However, most of the intragenic polymorphisms were in linkage disequilibrium and others were less frequent, thereby limiting or precluding the use of this approach for most AIP families. To date, common mutations have been identified only in a few ethnic or demographic groups; these include Swedish (W198X), ${ }^{23}$ Dutch (R116W), ${ }^{24}$ and Argentinean 
Table 2

HMB-synthase mutations in the unrelated AIP probands

\begin{tabular}{|c|c|c|c|c|c|c|}
\hline Proband & Exon/intron & Position cDNA nt & Nucleotide change (nt) & Mutation designation & Effect on coding sequence & Reference \\
\hline 1 & Exon 6 & 232 & $\mathrm{ACC} \rightarrow \mathrm{CCC}$ & T78P & $\mathrm{Thr} \rightarrow$ Pro at 78 & This report \\
\hline 2 & Exon 6 & 239 & $\mathrm{GAG} \rightarrow \mathrm{GGG}$ & E80G & Glu $\rightarrow$ Gly at 80 & This report \\
\hline 3 & Exon 7 & 331 & $\mathrm{GGA} \rightarrow \mathrm{AGA}$ & Gl11R & Gly $\rightarrow$ Arg at 111 & 20 \\
\hline 4 & Exon 10 & 517 & $\mathrm{CGG} \rightarrow \mathrm{TGG}$ & $\mathrm{R} 173 \mathrm{~W}$ & $\operatorname{Arg} \rightarrow \operatorname{Trp}$ at 173 & 21 \\
\hline 5 & Intron 1 & $33+1$ & $\mathrm{gt} \rightarrow \mathrm{at}$ & IVS $^{+1}$ & $5^{\prime}$ donor splice site mutation & 22 \\
\hline
\end{tabular}

a.

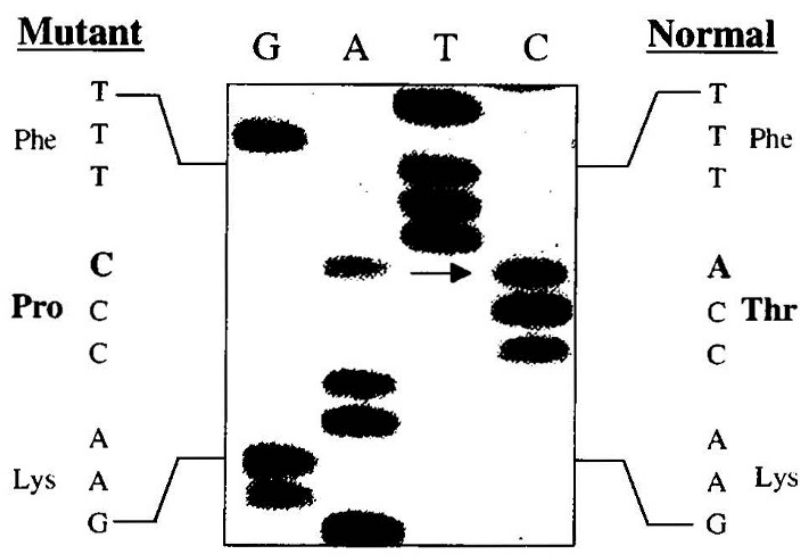

b.

E80G

Fig. 1 Partial sequencing gels of the HMB-synthase gene showing: (a) an A to $\mathrm{C}$ transversion of $\mathrm{CDNA}$ nt 232 in exon 6 predicting a threonine to proline substitution at residue 78 (T78P) in Proband 1, and (b) an A to G transition of cDNA nt 239 in exon 6 predicting a glutamic acid to glycine substitution at residue 80 (E80G) in Proband 2.

Table 3

Expression of HMB-synthase mutations $\mathrm{T} 78 \mathrm{P}$ and $\mathrm{E} 80 \mathrm{G}$ in E. coli

\begin{tabular}{lrcc}
\hline & \multicolumn{2}{c}{$\begin{array}{c}\text { HMB-synthase activity } \\
\text { (U/mg) }\end{array}$} & $\begin{array}{c}\text { \% of mean normal } \\
\text { expressed activity }\end{array}$ \\
\cline { 2 - 3 } Construct & Mean & Range & 100 \\
\hline pKK-HMBS & 146.0 & $122.0-171.0$ & 2.5 \\
pKK-HMBS-T78P & 3.6 & $3.47-3.76$ & 2.4 \\
\hline
\end{tabular}

${ }^{a}$ Mean and range based on results of three independent experiments.

(G111R $)^{18}$ AIP families, each of which presumably had a common founder. Thus, the precise diagnosis of AIP heterozygotes requires the identification of the specific $\mathrm{HMB}$-synthase lesions in each family.

Of the five mutations identified in this study, T78P and E80G were novel missense mutations that both occurred in exon 6 , seven nucleotides apart. These are only the second and third mutations to be identified in exon 6 and both involve highly conserved amino acids. Threonine-78 was found in 11 of $19 \mathrm{HMB}$-synthase orthologues with valine present in the other eight, while glutamic acid-80 was conserved in 17 of 19 orthologues. The E. coli HMB-synthase crystal structure, which has been solved at $1.76 \AA$ resolution, ${ }^{25}$ had three do- mains, each containing $\beta$-sheets, $\alpha$-helices, and a discrete hydrophobic core, with mainly polar contacts between the domains. ${ }^{25-27}$ Because there is 35\% homology and $>70 \%$ similarity between the predicted $E$. coli and human amino acid sequences, structure/function relationships can be inferred for certain human mutations. ${ }^{26,27}$ Molecular modeling of the T78P and E80G lesions revealed that the T78P mutation occurred at a $\beta$-turn just before the second $\alpha$-helix of domain 1, while the E80G substitution was within the $\alpha$-helix. The T78P and G80G lesions are both predicted to effect the stability, if not the formation, of this short, eight residue $\alpha$-helix. The T78P mutation would be expected to alter the formation of the helix, and possibly exist in conformational heterogeneity between the cis and trans forms, thereby altering the subtype of the $\beta$-turn before the start of the helix. The E80G mutation would disrupt the middle of the first turn of this two turn helix as predicted by the low probability of glycine existing in an $\alpha$-helical conformation. That these missense mutations would alter the enzyme structure and stability is consistent with the finding that both expressed mutations had markedly decreased activities.

Two of the previously described mutations, G111R, $, 9,18,20$ and $\mathrm{R} 173 \mathrm{~W},{ }^{21}$ caused classic disease, whereas the IVS1 ${ }^{+1} 22$ lesion occurred in a variant AIP patient. The R173W lesion occurred at a CpG dinucleotide, a known hot spot for muta- 


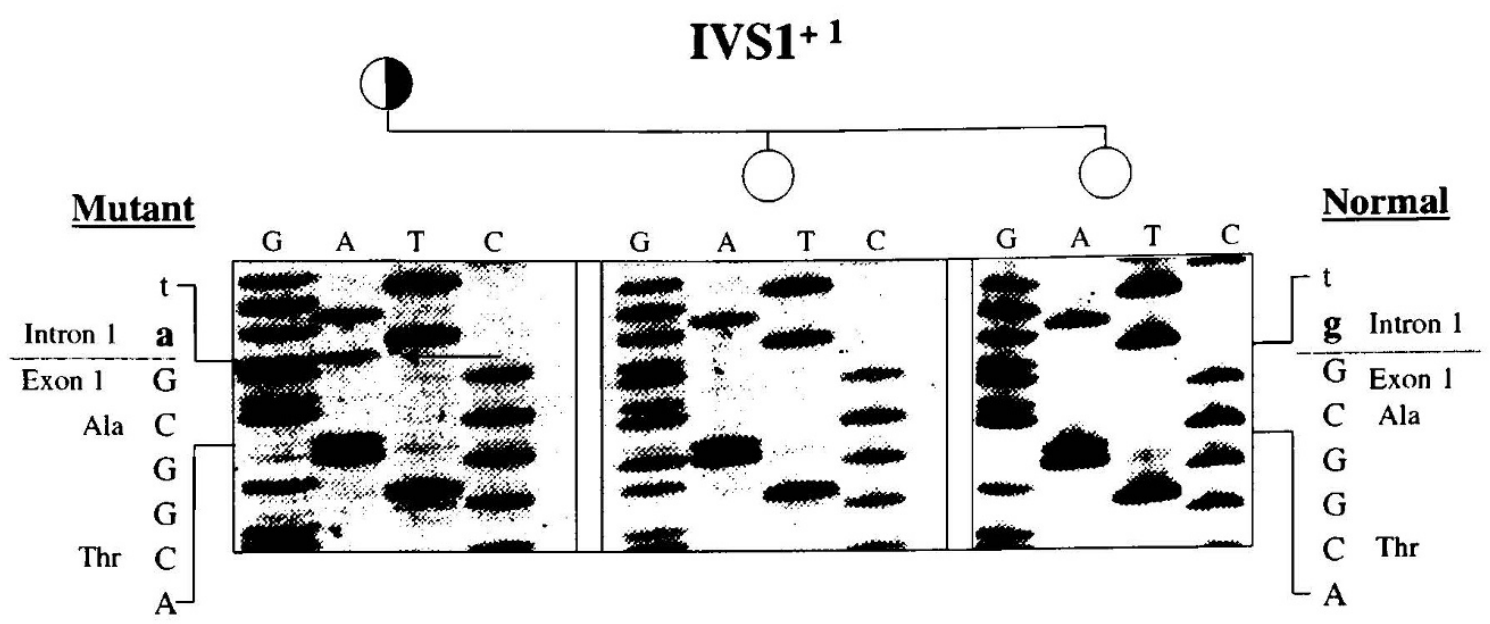

Fig. 2 Partial sequencing gel of the HMB-synthase gene from Proband 5 with variant AIP showing the $g$ to a transversion in the invariant 5' donor splice site of intron 1 (IVS1 ${ }^{-1}$ ).
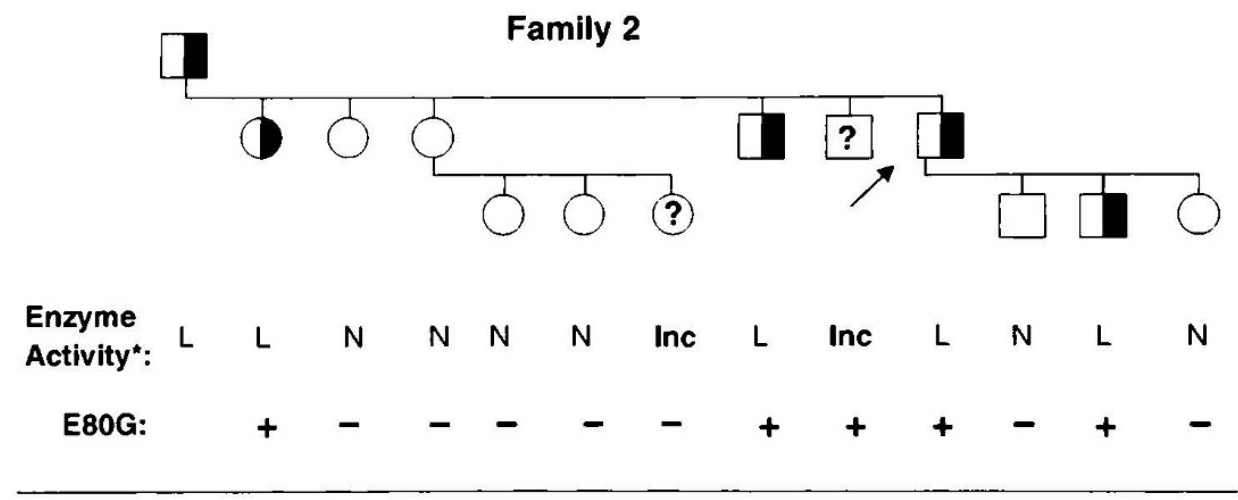

Fig. 3 Pedigree of Family 2. The reported erythrexyte HMB-synthase enzyme activities' and the presence or absence of the E80G mutation in each family member are indicated. AlP heterozygotes are shown by half-solid symbols. Enzymatic activity: $\mathrm{N}=$ normal. $\mathrm{L}=\mathrm{low}$, and Inc $=$ inconclusive

tions due to the deamination of methylcytosine to thymidine. ${ }^{28}$ In fact, $26 \%$ of the reported HMB-synthase single base substitutions involve exonic $\mathrm{CpG}$ dinucleotides, ${ }^{17}$ indicating that these dinucleotides are frequent sites in the HMB-synthase gene for mutations causing AIP. The Gl11R mutation, detected in Family 3, which had French ancestry, was previously identified in AIP patients from Belgium, ${ }^{20}$ France, ${ }^{4}$ and, most recently, in Argentinean AIP patients of European descent. ${ }^{18}$

In classic AIP families, identification of the specific causative mutations permits the precise diagnosis of heterozygotes who can be counseled to avoid the factors that precipitate acute attacks. Enzyme diagnosed individuals may be reassessed to clarify a borderline enzyme result or to confirm previous diagnoses. The identification of the E80G mutation in Family 2 from a large previously studied AIP family confirmed the earlier enzyme diagnoses of the eight family members available for our studies. ${ }^{4}$ Of note, a niece of proband 2 had erythrocyte HMB-synthase activity in the inconclusive range and thus was thought to be a risk for $\mathrm{AIP}^{4}$ However, mutation analysis revealed that her mother did not have the E80G mutation, thus clarifying the niece's genotype.
As noted above, the enzymatic diagnosis of families with variant AIP is not possible as they have normal erythrocyte HMB-synthase activity as exemplified by the proband from Family 5. The identification of the IVSI ${ }^{+1}$ mutation 22 in this family permitted the molecular diagnosis of the proband's daughters, neither of whom inherited the IVS ${ }^{+1}$ mutation (Fig. 2). The $\mathrm{IVSI}^{+1} 5^{\prime}$ donor splice site mutation was previously reported in one unrelated AIP family. ${ }^{9}$ To date, six other mutations causing variant AIP have been identified, five splice site lesions $\left(\operatorname{IVSl}^{-1}, 29 \operatorname{IVS}^{-2}, 30 \operatorname{IVS}^{+2}, 31\right.$ IVS $1^{+3}, 3^{30}$ and $\operatorname{IVS}_{1}{ }^{+5}{ }_{31}$ ), which like the IVS $1+1$ mutation result in an abnormal housekeeping transcript and no housekeeping enzyme, and an alteration of the initiation ATG in exon 1, which precludes normal translation of the housekeeping isozyme. ${ }^{14}$

In summary, two new mutations and three previously reported mutations causing AIP were identified in probands from five unrelated AIP families. Identification of these mutations highlights the molecular heterogeneity underlying AIP, permits the precise diagnosis of asymptomatic heterozygotes in these AIP families, and provides information for future structure-function studies of the human enzyme. 


\section{Acknowledgments}

This research was supported in part by grants from the National Institutes of Health, including a research grant (5 R01 DK26824), grants from the National Center for Research Resources for the General Clinical Research Centers at the Mount Sinai School of Medicine (5 M01 RR00071) and the University of Texas Medical Branch (5 M01 RR00073), a grant for the Mount Sinai Child Health Research Center (5 P30 HD28822), and a grant from the American Porphyria Foundation. L.C. is supported by a grant from the Portuguese Foundation for Science and Technology (Programa Praxis XXI). The authors thank Dr. Constanza Solis and the late Mr. Raman Reddy for their help and advice. The authors thank Dr. Fred Gilbert (New York, New York) for referral of an AIP patient.

\section{References}

1. McGovern MM, Anderson KE, Astrin KH, Desnick RJ. Inherited porphyrias. In Rimoin DL, Conner IM, Pyeritz RE, editors. Emery and Rimoin's principles and practice of medical genetics. Edinburgh: Churchill Livingston, 1996:2009-2036.

2. Kappas A, Sassa S, Galbraith RA, Nordmann Y. The porphyrias. In: Scriver CR, Beaudet AL, Sly WS, Valle D, editors. The metabolic and molecular bases of inter ited disease, 7th ed. New York: McGraw-Hill, 1995:1305-1365.

3. Anderson KE, Sassa S, Bishop DF, Desnick RJ. Disorders of heme biosynthesis: $\mathrm{X}$-linked sideroblastic anemia and the porphyrias. In: Scriver C, Beaudet A, Sly W, Valle D, Kinzler $\mathrm{K}$, Vogelstein B, editors. The metabolic and molecular bases of inherited diseases, 8 th ed. New York: McGraw-Hill, in press.

4. Bottomley SS, Bonkowsky HL, Kreimer-Birnbaum M. The diagnosis of acute intermittent porphyria: usefulness and limitations of the erythrocyte uroporphyrinogen I synthase assay. Am J Clin Pathol 1981;76:133-139.

5. Bonaiti-Pellie C, Phung L, Nordmann Y. Recurrence risk estimation of acute intermittent porphyria based on analysis of porphobilinogen deaminase activity: a bayesian approach. Am J Med Genet 1984;19:755-762.

6. Lamon JM, Frykholm BC, Tschudy DP. Family evaluations in acute intermittent porphyria using red cell uroporphyrinogen I synthetase. I Med Genet 1979;16:134139.

7. McColl KE, Moore MR, Thompson GG, Goldberg A. Screening for latent acute intermittent porphyria: the value of measuring both leucocyte delta-aminolaevu linic acid synthase and erythrocyte uroporphyrinogen-1-synthase activities. / Med Genet 1982;19:271-276.

8. Pierach CA, Weimer MK, Cardinal RA, Bossenmaier C, Bloomer JR. Red blood cell porphobilinogen deaminase in the evaluation of acute intermittent porphyria IAMA 1987;257:60-62.

9. Puy H, Deybach IC, Lamoril J, Robreau AM, Da Silva V, Gouya L, Grandchamp B Nordmann Y. Molecular epidemiology and diagnosis of PBG deaminase gene defects in acute intermittent porphyria. Am J Hum Genet 1997;60:1373-1383.

10. Raich N, Romeo PH, Dubart A, Beaupain D, Cohen-Solal M, Goossens M. Molecular cloning and complete primary sequence of human erythrocyte porphobilinogen deaminase. Nucleic Acids Res 1986;14:5955-5968.

11. Grandchamp B, De Verneuil H, Beaumont C, Chretien S, Walter O, Nordmann Y. Tissue specific expression of porphobilinogen deaminase: two isoenzymes from a single gene. Eur / Biochem 1987;162:105-110.

12. Chretien S, Dubart A, Beaupain D, Raich N, Grandchamp B, Rosa I, Goossens M, Romeo PH. Alternative transcription and splicing of the human porphobilinogen deaminase gene result either in tissue specific or in housekeeping expression. Pro
Natl Aad Sci USA 1988:85:6-10.

13. Yoo HW, Warner CA, Chen $\mathrm{CH}$, Desnick RJ. Hydroxymethylbilane synthase: com plete genomic sequence and amplifiable polymorphisms in the human gene. Gentomics 1993;15:21-29.

14. Mustajoki P. Normal erythrocyte uroporphyrinogen I synthase in a kindred with acute intermittent porphyria. Ann Intern Med 1981;95:162-166.

15. Astrin $\mathrm{KH}$, Desnick RJ. Molecular basis of acute intermittent porphyria: mutations and polymorphisms in the human hydroxymethylbilane synthase gene. Hum Mutat 1994:4:243-252.

16. Grandchamp B. Acute intermittent porphyria. Semin Liver Dis 1998;18:17-24.

17. Human Gene Mutation Database. Cardiff, Wales. Institute of Medical Genetics, 1997. http.//www.uwcm.ac.uk/uwcm/mg/hgmd0.html.

18. De Siervi A, Rossetti MV, Parera VE, Astrin KH, Aizencang GI, Glass IA, del CBAM, Desnick RJ. Identification and characterization of hydroxymethylbilane synthase mutations causing acute intermittent porphyria: evidence for an ancestral founder of the common G111R mutation. Am J Med Genet 1999;86:366-375.

19. Chen $\mathrm{C}-\mathrm{H}$, Astrin $\mathrm{KH}$, Lee G, Anderson KE, Desnick RJ. Acute intermittent porphyria: identification and expression of exonic mutations in the hydroxymethylbilane synthase gene: an initiation codon missense mutation in the housekeeping transcript causes "variant acute intermittent porphyria" with normal expression of the erythroid-specific enzyme. J Clin Inest 1994;94:1927-1937.

20. Gu XF, De Rooij F, De Baar E, Bruyland M, Lissens W, Nordmann Y, Grandchamp B. Two novel mutations of the porphobilinogen deaminase gene in acute intermittent porphyria. Hum Mol Genet 1993;2:1735-1736.

21. Mgone CS, Lanyon WG, Moore MR, Louie GV, Connor JM. Identification of five novel mutations in the porphobilinogen deaminase gene. Hum Mol Genet 1994;3: 809-811.

22. Grandchamp B, Picat C, Mignotte V, Wilson JHP, Tevelde $k$, Sandkuyl L, Romeo $\mathrm{PH}$, Goossens M. Nordmann Y. Tissue-specific splicing mutation in acute intermittent porphyria. Proc Nat Acad Sci USA 1989;86:661-664.

23. Lee IS, Anvret M. Identification of the most common mutation within the porphobilinogen deaminase gene in Swedish patients with acute intermittent porphyria. Proc Natl Acud Sci USA 1991;88:10912-10915.

24. Gu XF, De Rooij F, Lee IS, Velde KT, Deybach JC, Nordmann Y, Grandchamp B. High prevalence of a point mutation in the porphobilinogen deaminase gene in Dutch patients with acute intermittent porphyria. Hum Genet 1993;91:128-130.

25. Louie GV, Brownlie PD, Lambert R, Cooper IB, Blundell TL, Wood SP, Warren MJ, Woodcock SC, Jordan PM. Structure of porphobilinogen deaminase reveals a flexible multidomain polymerase with a single catalytic site. Nature 1992:359:33-39.

26. Brownlie PD, Lambert R, Louie GV, Jordan PM, Blundell TL, Warren MI, Cooper JB, Wood SP. The three-dimensional structures of mutants of porphobilinogen deaminase: toward an understanding of the structural basis of acute intermittent porphyria. Protein Sit 1994;3:1644-1650.

27. Wood S, Lambert R, Jordan M. Molecular basis of acute intermittent porphyria. Mol Med Today 1995;5:232-239.

28. Cooper DN. Youssoufian $\mathrm{H}$. The $\mathrm{CPG}$ dinucleotide and human genetic disease. Hum Genet 1988;78:151-155.

29. Grandihamp B, Picat C, De Rooii F, Beaumont C, Wilson P, Deybach IC, Nordmann $Y$. A point mutation $G->A$ in exon 12 of the porphobilinogen deaminase gene results in exon skipping and is responsible for acute intermittent porphyria. Nucleic Acids Res 1989:17:6637-6649.

30. Mustajoki S, Pihlaja H, Ahola H, Petersen NE, Mustajoki P, Kauppinen R. Three splicing defects, an insertion, and two missense mutations responsible for acute internittent porphyria. Hum Genet 1998;102:541-548.

31. Puy H, Gross U, Deybach IC, Robreau AM, Frank M. Nordmann Y, Doss M. Exon 1 donor splice site mutations in the porphobilinogen deaminase gene in the nonerythroid variant form of acute intermittent porphỵria. Hum Gentet 1998;103:570575 